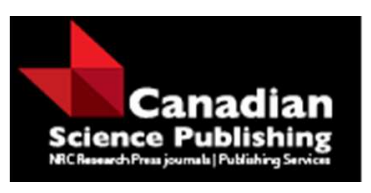

Canadian Journal of Physics

Revue canadienne de physique

\title{
Determination of Coherent to Compton Scattering Differential Cross-Section Ratios of some Inorganic Materials with EDXRF
}

\begin{tabular}{|r|l|}
\hline Journal: & Canadian Journal of Physics \\
\hline Manuscript ID & cjp-2016-0337.R2 \\
\hline Manuscript Type: & Article \\
\hline Date Submitted by the Author: & $30-$ Nov-2016 \\
\hline Complete List of Authors: & $\begin{array}{l}\text { YIlmaz, Demet; Ataturk Universitesi } \\
\text { Şimşek, Ümmuhan; Ataturk Uni. } \\
\text { Akkuş, Tuba; Ataturk Universitesi } \\
\text { Şahin, Yusuf; Ataturk Universitesi }\end{array}$ \\
\hline Keyword: & $\begin{array}{l}\text { Compton scattering, Coherent scattering, HPGe detector, Differential cross- } \\
\text { section ratios, Inorganic materials }\end{array}$ \\
\hline \multicolumn{2}{|c}{} \\
\hline
\end{tabular}

\section{SCHOLARONE" \\ Manuscripts}




\title{
Determination of Coherent to Compton Scattering Differential
}

\section{Cross-Section Ratios of some Inorganic Materials with EDXRF}

D. Yılmaz , Ü. Şimşek, T. Akkuş, Y. Şahin

\begin{abstract}
In this study, we aimed to determine coherent to Compton scattering differential cross-section ratios of some inorganic materials $\left(\mathrm{BaSO}_{4}, \mathrm{CaF}_{2}, \mathrm{Mg}_{2} \mathrm{SiO}_{4}, \mathrm{MgSO}_{4}\right.$ and $\mathrm{ZnSO}_{4}\left(7 \mathrm{H}_{2} \mathrm{O}\right)$ ) for several scattering angles $\left(95^{\circ}, 105^{\circ}, 115^{\circ}, 125^{\circ}\right.$ and $\left.135^{\circ}\right)$. Coherent to Compton scattering differential cross-section ratios were investigated experimentally by using HPGe detector, which has a resolution of $199.6 \mathrm{eV}$ at the $5.9 \mathrm{keV}$. The samples were excited with $59.54 \mathrm{keV}$ gamma rays emitted from $\mathrm{Am}^{241}$ point source. The intensity ratios were corrected due to the photopeak efficiency of gamma detector and absorption of photons in the target and air. It is observed that coherent to Compton scattering differential cross-section ratios decreases with the increasing scattering angle.
\end{abstract}

PACS Nos.: 32.30.Rj, 78.70.Ck

Keywords: Compton scattering, Coherent scattering, HPGe detector; Differential cross-section ratios; Inorganic materials

\footnotetext{
* D. YIlmaz. Atatürk University, Faculty of Sciences, Department of Physics, Erzurum, Turkey. e-mail for correspondence: ddemir@atauni.edu.tr
} 


\section{Introduction}

The photoelectric effect, scattering (coherent and Compton) and the pair production process are the fundamental interactions between the photons and atoms. Photo absorption may dominate up to $400-500 \mathrm{keV}$. The photoelectric effect is the predominant process especially with high $\mathrm{Z}$ elements. Above $1.022 \mathrm{MeV}$, the pair production is the interaction process between photons and atoms. Above $60 \mathrm{keV}$, the most predominant photon interaction mode is coherent and Compton scattering. If the photons are scattered from tightly bound electrons of an atom, there will be no excitation and coherent scattering is produced. The scattered photons will have the same energy with the incident beam. Compton scattering is the scattering of a photon of high energy from an electron (resulting in a loss of energy) considered being free and stationary or from an atomic electron whose binding energy is small compared with the incident photon energy.

Coherent and Compton scattering are major processes to obtain information about the structural properties of matter, to characterize atomic number of materials and to determine several physical quantities such as electron momentum distributions in elements, compounds, metals and alloys. Coherent and Compton scattering cross-sections have played a central role in the understanding of the excited states of many important systems. Coherent and Compton scattering differential cross-sections are used in such diverse applications as medical X-ray technology, the calculation of radiation attenuation, power reactor shielding, industrial radiation processing, transport and energy deposition and analysis of nuclear physics experiments.

Coherent to Compton scattering intensity ratio is measured in order to assess trabecular bone mineral content [1]. Algoboory determined Compton and coherent scattering differential cross-sections for ${ }^{103} \mathrm{Rh}_{45}$ and ${ }^{181} \mathrm{Ta}_{73}$ in range of energy $1 \mathrm{keV}-1 \mathrm{MeV}$ [2]. Şimşek and Ertuğrul 
studied angular dependence of coherent to incoherent scattering differential cross-section ratios for $\mathrm{Zr}, \mathrm{Nb}$ and $\mathrm{Mo}$ elements [3]. İçelli and Erzeneoğlu measured coherent and incoherent scattering differential cross-sections for $\mathrm{Be}, \mathrm{Al}$ and $\mathrm{Au}$ in angles ranging from $45^{\circ}$ to $125^{\circ}$ [4]. Akkuş et al. measured polar $\left(90^{\circ}, 100^{\circ}, 110^{\circ}, 120^{\circ}\right.$ and $\left.130^{\circ}\right)$ and azimuthal $\left(30^{\circ}, 20^{\circ}, 10^{\circ}, 0^{\circ}\right.$, $10^{\circ},-20^{\circ}$ ) angular dependence of coherent to incoherent scattering differential cross-section ratios of $\mathrm{Au}$ at $59.54 \mathrm{keV}$ photon energy [5]. Demir and Turşucu determined effective atomic number of $\mathrm{Fe}_{\mathrm{x}} \mathrm{Cr}_{1-\mathrm{x}}$ and $\mathrm{Fe}_{\mathrm{x}} \mathrm{Ni}_{\mathrm{x}}$ alloys by using scattering of gamma rays [6]. Y1lmaz et al. investigated effective atomic number of gunshot residues by using scattering of gamma rays [7]. Singh et al. investigated coherent to incoherent scattering cross-sections of some scientific interest samples (oxides of lanthanides and alloys of lead and tin of known composition) by 145 $\mathrm{keV}$ incident gamma photons [8]. Also, stable iodine content of tissue was measured in this work. The authors used coherent to incoherent scattering cross-sections to calculate the effective atomic number $\left(\mathrm{Z}_{\mathrm{eff}}\right)$ of samples. Poletti et al. studied coherent and incoherent scattering of 17.44 and $6.93 \mathrm{keV} x$-ray photons scattered from biological and biological-equivalent samples [9]. The authors show that it is important the angular distribution of photons scattered for material characterizing.

Inorganic materials such as $\mathrm{BaSO}_{4}, \mathrm{CaF}_{2}, \mathrm{Mg}_{2} \mathrm{SiO}_{4}, \mathrm{MgSO}_{4}$ and $\mathrm{ZnSO}_{4}\left(7 \mathrm{H}_{2} \mathrm{O}\right)$ are used in thermoluminescent dosimeter. Thermoluminescent dosimeter (TLD) is a small device used to measure radiation by measuring the amount of visible light emitted from a crystal in the detector when exposed to ionizing radiation. TLD's are widely used in many areas such as cancer treatment using radiotherapy, clinical diagnostic radiology, radiotherapy mailed dosimetry, environmental radiation monitoring, industrial applications such as food irradiation and sterilization of health care products, the fields of environmental, industrial and personnel 
applications. Differential scattering cross-sections of TLD materials cannot be found in standard reference database, but they are necessary for many applications in radiation dosimetry and therapy.

In this study, we aimed to determine coherent to Compton scattering differential crosssection ratios of some TLD materials such as $\mathrm{BaSO}_{4}, \mathrm{CaF}_{2}, \mathrm{Mg}_{2} \mathrm{SiO}_{4}, \mathrm{MgSO}_{4}$ and $\mathrm{ZnSO}_{4}\left(7 \mathrm{H}_{2} \mathrm{O}\right)$. The targets were excited with $59.54 \mathrm{keV}$ gamma rays emitted from $3.7 \times 10^{9} \mathrm{~Bq}(100 \mathrm{mCi}) \mathrm{Am}^{241}$ point source. Coherent to Compton scattering differential cross-section ratios were investigated for several scattering angles $\left(95^{\circ}, 105^{\circ}, 115^{\circ}, 125^{\circ}\right.$ and $\left.135^{\circ}\right)$. The scattered radiations are detected by using high purity germanium (HPGe) detector, which has a resolution of $199.6 \mathrm{eV}$ at the $5.9 \mathrm{keV}$. Coherent to Compton scattering intensity ratios were corrected due to the photopeak efficiency of gamma detector and absorption of photons in the target and air.

\section{Theory}

Theoretically, coherent scattering differential cross-sections is given as

$\frac{d \sigma_{c o h}}{d \Omega}=\frac{r_{0}^{2}}{2}\left(1+\cos ^{2} \theta\right)|F(q, Z)|^{2}$

where $F(q, Z)$ is the atomic form factor and $r_{0}^{2}=2.8179 \times 10^{-15} \mathrm{~m}$ is the classical electron radius. $q$ represents the momentum transferred to the electron and $q$ is measured in units of $1 / \AA$ as follows:

$q=(\sin \theta / 2)(1 / \lambda)$ 
where $\lambda$ is the incident photon's wavelength and $\theta$ is the angle of scattering. The atomic Compton scattering can be calculated with the incoherent scattering function modification to Klein-Nishina formula for Compton (single, free electron) scattering:

$\left(\frac{d \sigma}{d \Omega}\right)_{\text {Comp }}=S(q, Z)\left(\frac{d \sigma}{d \Omega}\right)_{K N}$

where $S(q, Z)$ is the incoherent scattering function. Coherent to Compton scattering crosssection ratio becomes

$$
\frac{d \sigma_{c o h}}{d \sigma_{\text {Comp }}} \propto \frac{|F(q, Z)|^{2}}{S(q, Z)}
$$

Coherent to Compton scattering cross-section ratio has a power relation to $Z$ in the region of elemental interest and this power dependence is based upon the ratio $F^{2} / S$. The theoretical values of the atomic form factor and the incoherent scattering function were obtained Hubbell et al. [10].

\section{Experimental details}

In scattering experiments, the intensities of coherent and Compton scattered gamma photons at a particular scattering angle are detected. The intensity of coherent and Compton peaks should be sufficient and the two peaks must be well separated from each other in $\mathrm{x}$-ray spectrum. The experimental setup used in the present work is shown in Fig. 1. The angle of scattering are measured in the range $95^{\circ} \leq \theta \leq 135^{\circ}$ with $10^{\circ}$ steps. While the detector and the sample were kept in a fixed position, the radioactive source was rotated around the $y$-axis to obtain the spectral distribution to obtain the polar angle distribution. 
Inorganic materials $\left(\mathrm{BaSO}_{4}, \mathrm{CaF}_{2}, \mathrm{Mg}_{2} \mathrm{SiO}_{4}, \mathrm{MgSO}_{4}\right.$ and $\left.\mathrm{ZnSO}_{4}\left(7 \mathrm{H}_{2} \mathrm{O}\right)\right)$ of mass thickness ranging from 0.189 to $0.372 \mathrm{~g} / \mathrm{cm}^{2}$ were prepared in this work as seen from Table 1 . The samples were prepared in the form of $0.65 \mathrm{~mm}$ radius cylindrical pellets by pressing in a hand-operated hydraulic press at a pressure of 8 ton. The samples were excited with $59.54 \mathrm{keV}$ gamma rays emitted from $3.7 \times 10^{9} \mathrm{~Bq}(100 \mathrm{mCi}) \mathrm{Am}^{241}$ point source. Coherent and Compton peaks were acquired by a PGT HPGe detector. This detector has a resolution of $199.6 \mathrm{eV}$ at the $5.9 \mathrm{keV}$, active area of $200 \mathrm{~mm}^{2}$ and beryllium window of $12.5 \mu \mathrm{m}$ thickness. The pulse height spectra of X-rays were acquired for a period of 3600 s. Background spectrum was measured for each angle and subtracted from total pulse-height raw spectrum. Operating parameters of the system are governed and controlled by the computer program Genie 2000. The data were collected into 4096 channels of the MCA. Data were analyzed by Origion 7.5 software program. A typical spectrum of $\mathrm{CaF}_{2}$ target is shown in Fig. 2.

The intensity of coherent and Compton scattered peaks are corrected for photo peak efficiency, absorption in air between target and the detector and self-absorption in the target as follows:

$$
N_{\text {actual }}=\frac{N_{o b s}}{\varepsilon_{\gamma} \beta_{\gamma a} \beta_{\gamma t}}
$$

where $N_{o b s,} \varepsilon_{\gamma}, \beta_{\gamma a}$ and $\beta_{\gamma t}$ are observed intensity under coherent or Compton peak, photo peak efficiency of gamma detector for coherent or Compton scattered photons, correction factor for absorption of photons in air between target and detector and self-absorption correction factor for scattered photons in the target, respectively. The ratio of coherent to Compton scattering crosssection is given as follows: 
$\frac{d \sigma_{\text {coh }}}{d \sigma_{\text {Comp }}}=\frac{N_{\text {coh }} \beta_{\gamma a(\text { Comp })} \beta_{\gamma t(\text { Comp })} \varepsilon_{\gamma(\text { Comp })}}{N_{\text {Comp }} \beta_{\gamma a(\text { coh })} \beta_{\gamma t(\text { coh })} \varepsilon_{\gamma(\text { coh })}}$

where $N_{\text {con }} / N_{\text {Comp }}$ is the ratio of the number of counts under coherent and Compton scattered peaks, $\beta_{\gamma a(c o h)} / \beta_{\gamma a(\text { Comp })}$ is the ratio of the air absorptions for coherent scattered and Compton scattered gamma rays in air, $\beta_{\gamma t(\text { coh })} / \beta_{\gamma t(\text { Comp })}$ is the ratio of self-absorption correction factors in the target for coherent and Compton scattered photons and $\varepsilon_{\gamma(\text { cooh })} / \varepsilon_{\gamma(\text { Comp })}$ is the ratio of photopeak efficiencies of the HPGe detector for coherent and Compton scattered photons. The self-absorption correction factors in the target and the air absorption correction were calculated using the works of Akkuş et al. [5]. In this work, the values of mass attenuation coefficients are taken from WinXCOM [11]. The photopeak efficiency was obtained experimentally in the range 26.345-661.657 $\mathrm{keV}$ photon energy by using $\mathrm{Am}^{241}, \mathrm{Ba}^{133}, \mathrm{Eu}^{152}$ and $\mathrm{Cs}^{137}$ radioactive calibration sources. The photopeak efficiency curve for the HPGe detector is shown in Fig. 3. Each of these radioactive sources of known activity was placed at position of the target and the energy spectra were recorded by the HPGe detector. The photopeak efficiency was determined using the works of Demir and Turşucu [6].

\section{Results and discussion}

The measured values of coherent to Compton scattering differential cross-section ratio for the inorganic materials $\left(\mathrm{BaSO}_{4}, \mathrm{CaF}_{2}, \mathrm{Mg}_{2} \mathrm{SiO}_{4}, \mathrm{MgSO}_{4}\right.$ and $\left.\mathrm{ZnSO}_{4}\left(7 \mathrm{H}_{2} \mathrm{O}\right)\right)$ at the scattering angles of $95^{\circ}, 105^{\circ}, 115^{\circ}, 125^{\circ}$ and $135^{\circ}$ are given in Figs $4-8$. There are no available data in literature for comparison with the present results. As seen from Figs 4-8, coherent to Compton scattering differential cross-section ratios decrease with increasing scattering angles. There is a 
good third order polynomial relation between differential cross-section ratios and scattering angles as follows:

$$
\begin{aligned}
& \frac{d \sigma_{(\text {coh })}}{d \sigma_{(\text {Comp })}}=35.30-0.808 \theta+0.006 \theta^{2}-1.651 \times 10^{-5} \theta^{3} \quad r^{2}=0.999 \\
& \frac{d \sigma_{(\text {coh })}}{d \sigma_{(\text {Comp })}}=-0.0088+5.761 \times 10^{-4} \theta-6.700 \times 10^{-6} \theta^{2}-2.274 \times 10^{-8} \theta^{3} \quad r^{2}=0.908 \quad \text { (for Fig. 5) } \\
& \frac{d \sigma_{(\text {coh })}}{d \sigma_{(\text {Comp })}}=0.0571-0.0014 \theta+1.118 \times 10^{-5} \theta^{2}-3.057 \times 10^{-8} \theta^{3} \quad r^{2}=0.999 \quad \quad \text { (for Fig. 6) } \\
& \frac{d \sigma_{(\text {coh })}}{d \sigma_{(\text {Comp })}}=0.0454-0.0011 \theta+9.091 \times 10^{-6} \theta^{2}-2.510 \times 10^{-8} \theta^{3} \quad r^{2}=0.981 \quad \text { (for Fig. 7) } \\
& \frac{d \sigma_{(\text {coh })}}{d \sigma_{(\text {Comp })}}=0.0363-8.540 \times 10^{-4} \theta+6.809 \times 10^{-6} \theta^{2}-1.824^{-8} \theta^{3} \quad r^{2}=0.995 \quad \text { (for Fig. 8) }
\end{aligned}
$$

The correlation theory is used to confirm this polynomial relation. Each correlation coefficient given is significant according to 5 percent confidence level. As seen from Eq. (6), coherent to Compton scattering differential cross-section ratios are not required the geometrical factors and incoming intensity of the exciting radiation. In this work, the intensity ratios were corrected due to the photopeak efficiency of gamma detector and absorption of photons in the target and air. Thus, variation of coherent to Compton scattering differential cross-section ratios with scattering angle gives more realistic results than the absolute differential cross-section. Also, this method is both very useful and practical for trace elemental analysis and quantitative analysis of inorganic materials. 
Mean atomic numbers and theoretical scattering cross-section ratios (WinXCOM [11]) of inorganic materials studied in the present work are given in Table 1. The theoretical scattering cross-section ratios generally decrease with the decreasing mean atomic numbers as seen from Table 1. Also, it is interesting to note that coherent to Compton scattering differential crosssection ratios decrease with the decreasing mean atomic numbers as seen from Table 1 and Figs. 4-8. To obtain and compare more sensitive values, more experimental study is need connected with inorganic materials of different mean atomic numbers.

The overall error in the experimental parameters is the sum of the uncertainties in different factors, namely, the evaluation of peak areas (2.21-3.39\%), absorption correction factor, (1.12$3.65 \%)$, determination of detector efficiency $(1.10-2.48 \%)$ and statistical error $(<1.00 \%)$. Total errors affecting the experimental parameters are calculated between $2.89-5.65 \%$.

\section{Conclusion}

In the present work, coherent to Compton scattering differential cross-section ratios of inorganic materials such as $\mathrm{BaSO}_{4}, \mathrm{CaF}_{2}, \mathrm{Mg}_{2} \mathrm{SiO}_{4}, \mathrm{MgSO}_{4}$ and $\mathrm{ZnSO}_{4}\left(7 \mathrm{H}_{2} \mathrm{O}\right)$ used in thermoluminescent dosimeter have been measured for several scattering angles $\left(95^{\circ}, 105^{\circ}, 115^{\circ}\right.$, $125^{\circ}$ and $\left.135^{\circ}\right)$ at $59.54 \mathrm{keV}$ photon energy by using HPGe detector. Am ${ }^{241}$ point source (100 $\mathrm{mCi}$ ) emitting $59.54 \mathrm{keV}$ gamma rays are used to excite the samples. Differential cross-sections are used in the present work because it is important the angular distribution of photons scattered for material characterizing. Also, variation of coherent to Compton scattering differential crosssection ratios with scattering angle gives more realistic results. The five fitting formulas between differential cross-section ratios and scattering angles in page 8 are extremely useful to calculate 
some atomic parameter such as effective atomic number and electron density. These empirical formulas may be used for semi-experimental measurements with small scattering angle.

The intensity ratios were corrected due to the photopeak efficiency of gamma detector and absorption of photons in the target and air. It is observed that coherent to Compton scattering differential cross-section ratios decrease with increasing scattering angles. Also, this ratio decreases with decreasing mean atomic number. Comparison with the existing experimental data has not been made since there are no earlier reports about coherent to Compton scattering differential cross-section ratio of inorganic materials at $59.54 \mathrm{keV}$ in the literature. The measured values can be used to determine physical quantities such as electron momentum distributions in compounds. 


\section{References}

1. D.J Webster and S.C. Lillicrap. Physics in Medicine and Biology. 30, 531 (1985). doi: 10.1088/0031-9155/30/6/003.

2. R.A.A. Algoboory. Baghdad Science Journal 9, 554 (2012). ISSN: P:20788665 $\mathrm{E}: 24117986$.

3. Ö. Şimşek and M. Ertuğrul. Radiation Measurements: 38, 271 (2004). doi: 10.1016/j.radmeas.2003.11.006.

4. O. İçelli and E. Erzeneoğlu. Journal of Quantitative Spectroscopy and Radiative Transfer 74, 531 (2002). doi:10.1016/S0022-4073(01)00266-7.

5. T. Akkuş, M.P. Dal, Y. Şahin. Radiation Physics and Chemistry 117, 167 (2015). doi: 10.1016/j.radphyschem.2015.08.014.

6. D. Demir and A. Tursucu. J. Alloy. Compd. 581, 213 (2013). doi:10.1016/j.jallcom.2013.07.057.

7. D. Yılmaz, A. Turşucu, Z. Uzunoğlu, D. Korucu. Radiation Physics and Chemistry 102, 68 (2014). doi:10.1016/j.radphyschem.2014.04.012.

8. M.P. Singh, A. Sharma, B. Singh, B.S. Sandhu. Radiation Measurements 45, 960 (2010) doi:10.1016/j.radmeas.2010.01.021.

9. E.M. Poletti, O.D. Gonçalves, I. Mazzaro. X-Ray Spectrometry 31, 57 (2002). doi: $10.1002 / x r s .538$.

10. J.H Hubbell, Wm. J. Veigele, E.A. Bringgs, R.T. Brown, D.T. Cromer, R.J. Hoverton. J. Phys. Chem. Ref. Data 4, 471 (1975). http://dx.doi.org/10.1063/1.555523.

11. L. Gerward, N. Guilber, K.B Jensen, H. Levring. Radiation Physics and Chemistry 60, 23 (2001). doi:10.1016/S0969-806X(00)00324-8. 


\section{FIGURE CAPTIONS}

Fig. 1. Experimental setup. T: Target, S: Am241 point source, $\theta$ : scattering angle.

Fig. 2. A typical spectrum from $\mathrm{CaF}_{2}$ target at scattering angle of $125^{\circ}$.

Fig. 3. The experimental photopeak efficiency curve for HPGe.

Fig. 4. Variation of coherent to Compton scattering cross-section ratio as a fuction of scattering angle for $\mathrm{BaSO}_{4}$.

Fig. 5. Variation of coherent to Compton scattering cross-section ratio as a fuction of scattering angle for $\mathrm{CaF}_{2}$.

Fig. 6. Variation of coherent to Compton scattering cross-section ratio as a fuction of scattering angle for $\mathrm{Mg}_{2} \mathrm{SiO}_{4}$.

Fig. 7. Variation of coherent to Compton scattering cross-section ratio as a fuction of scattering angle for $\mathrm{MgSO}_{4}$.

Fig. 8. Variation of coherent to Compton scattering cross-section ratio as a fuction of scattering angle for $\mathrm{ZnSO}_{4}\left(7 \mathrm{H}_{2} \mathrm{O}\right)$.

\section{TABLE CAPTIONS}

Table 1. Properties and theoretical cross-section ratios of inorganic materials. 


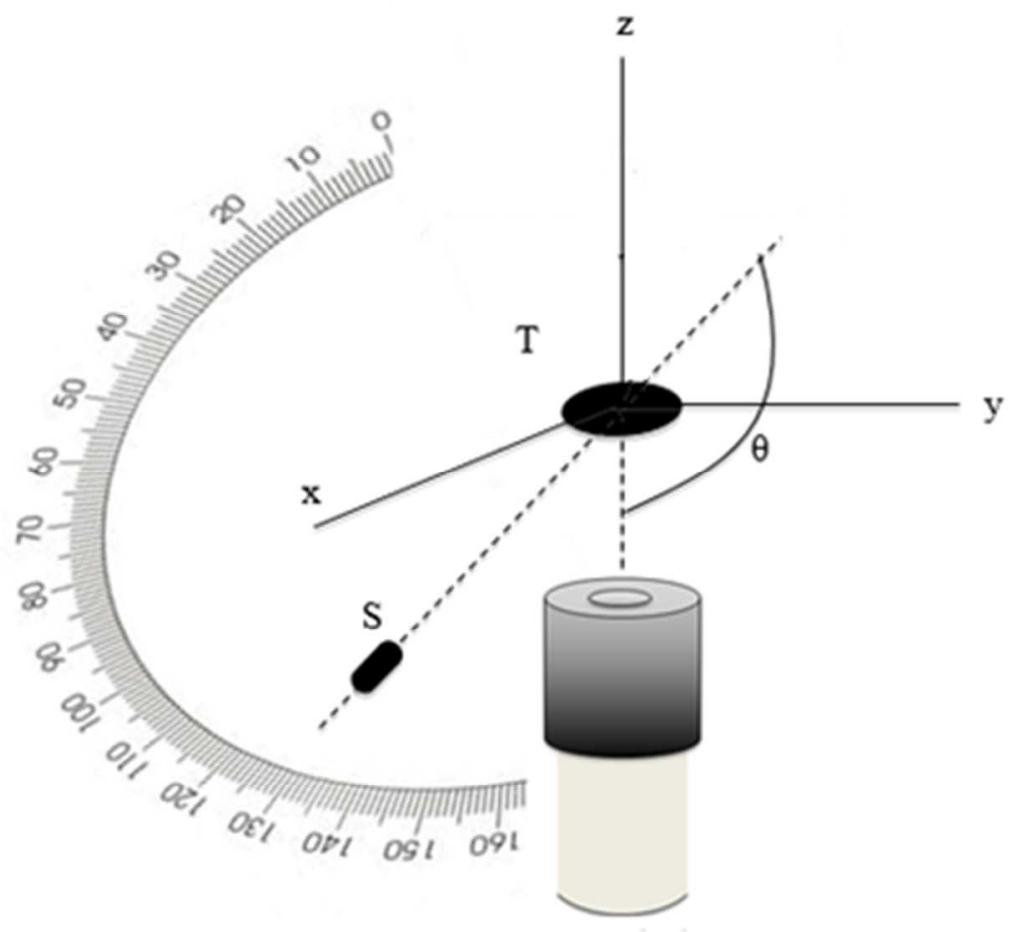

HPGe detector

Fig. 1. 


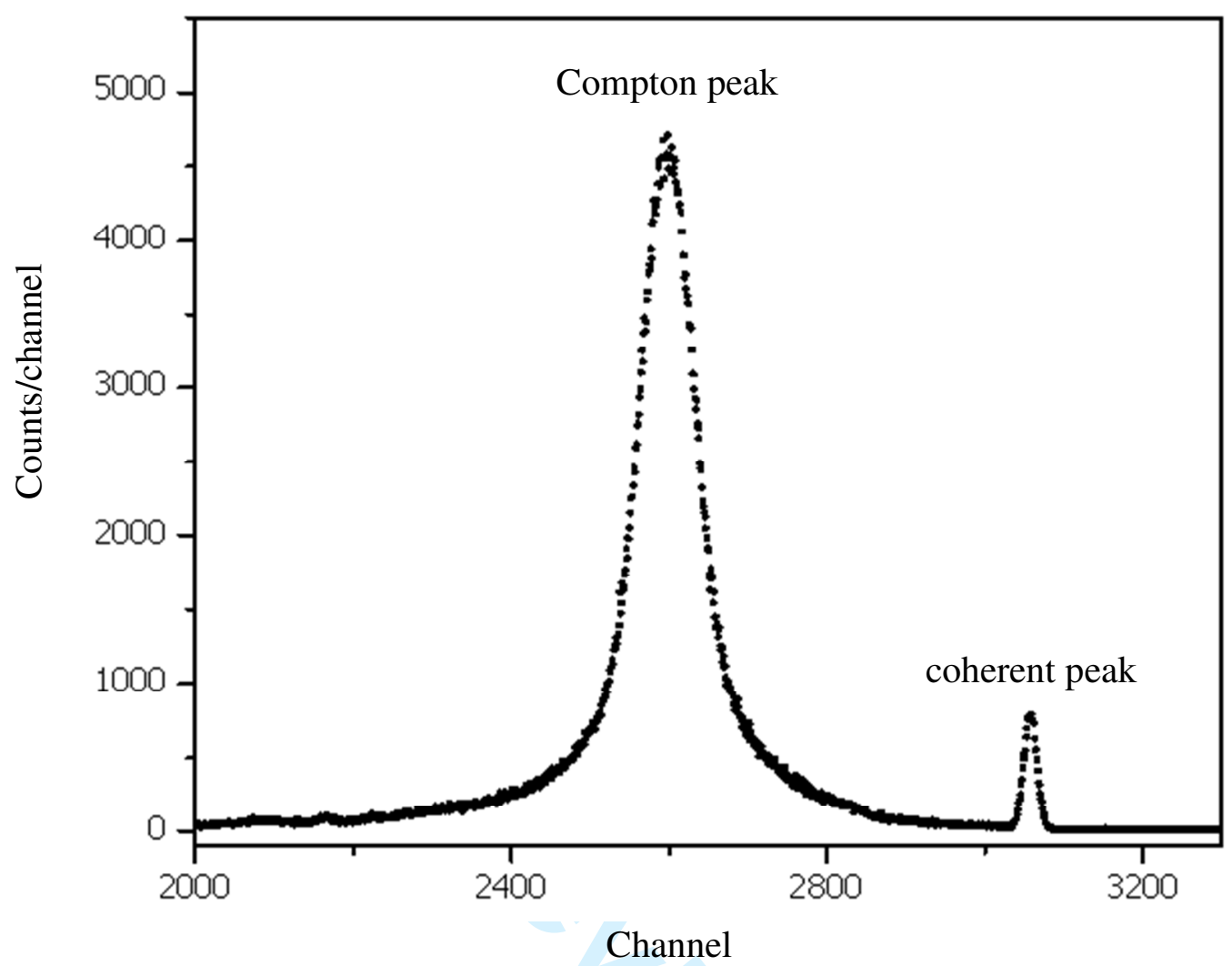

Fig. 2. 


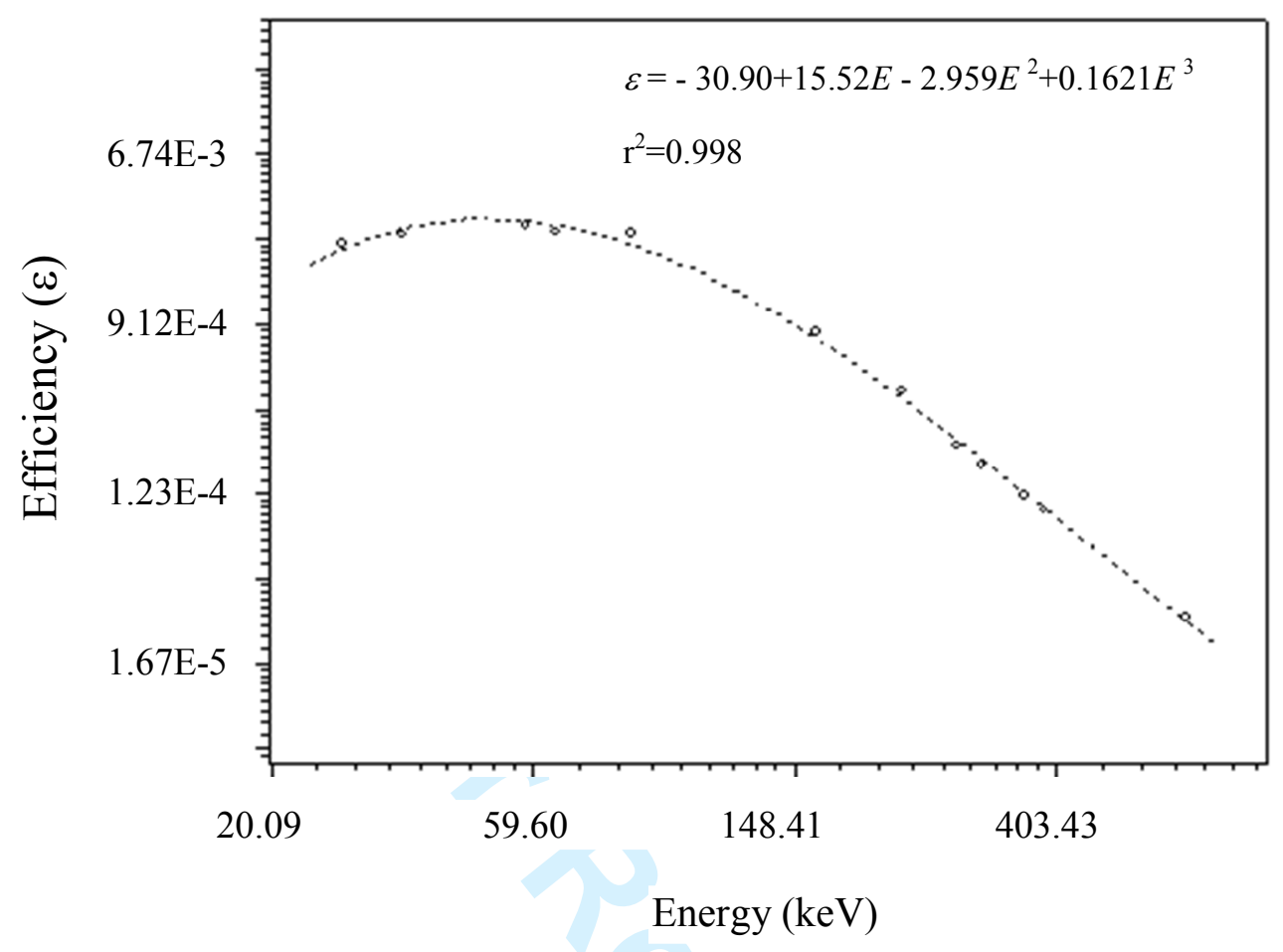

Fig. 3. 
Fig. 4.

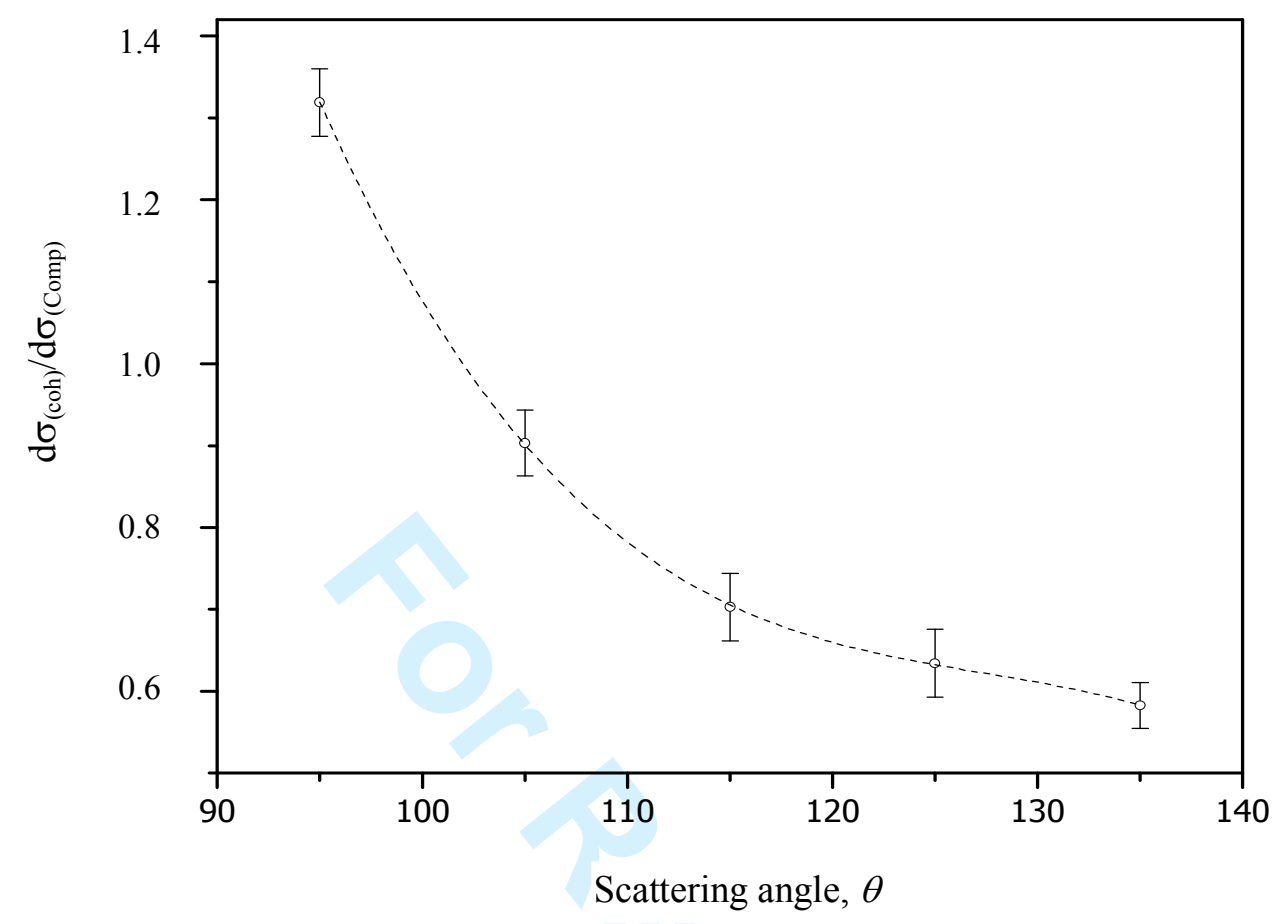

Fig. 4. 


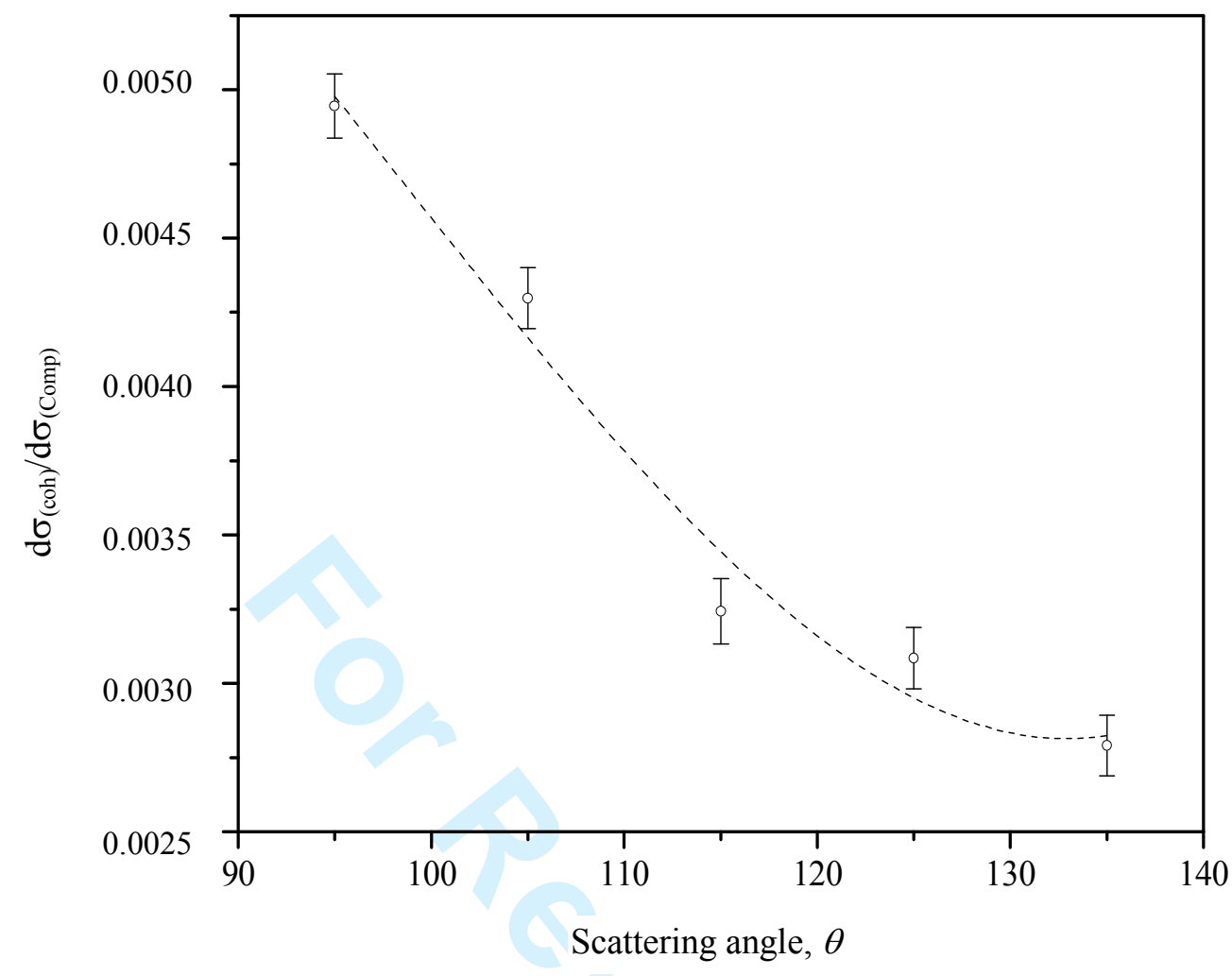

Fig. 5. 


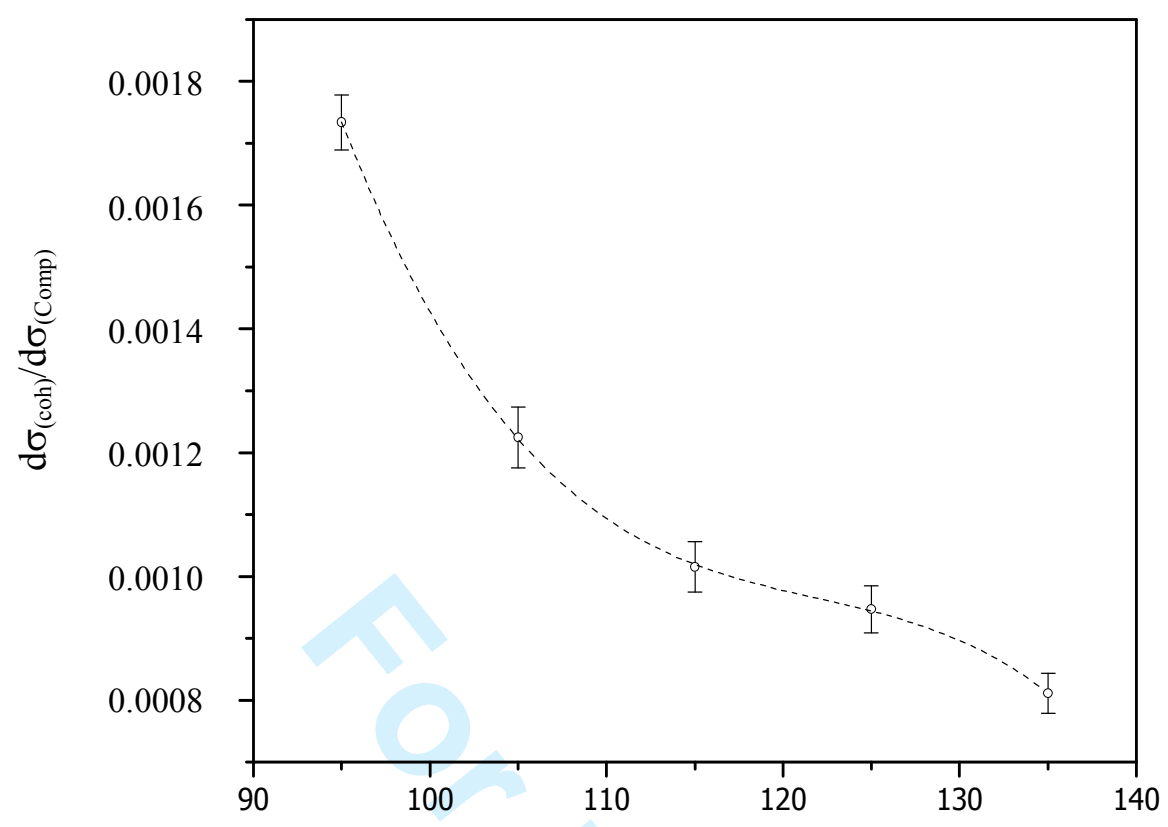

Scattering angle, $\theta$

Fig. 6. 


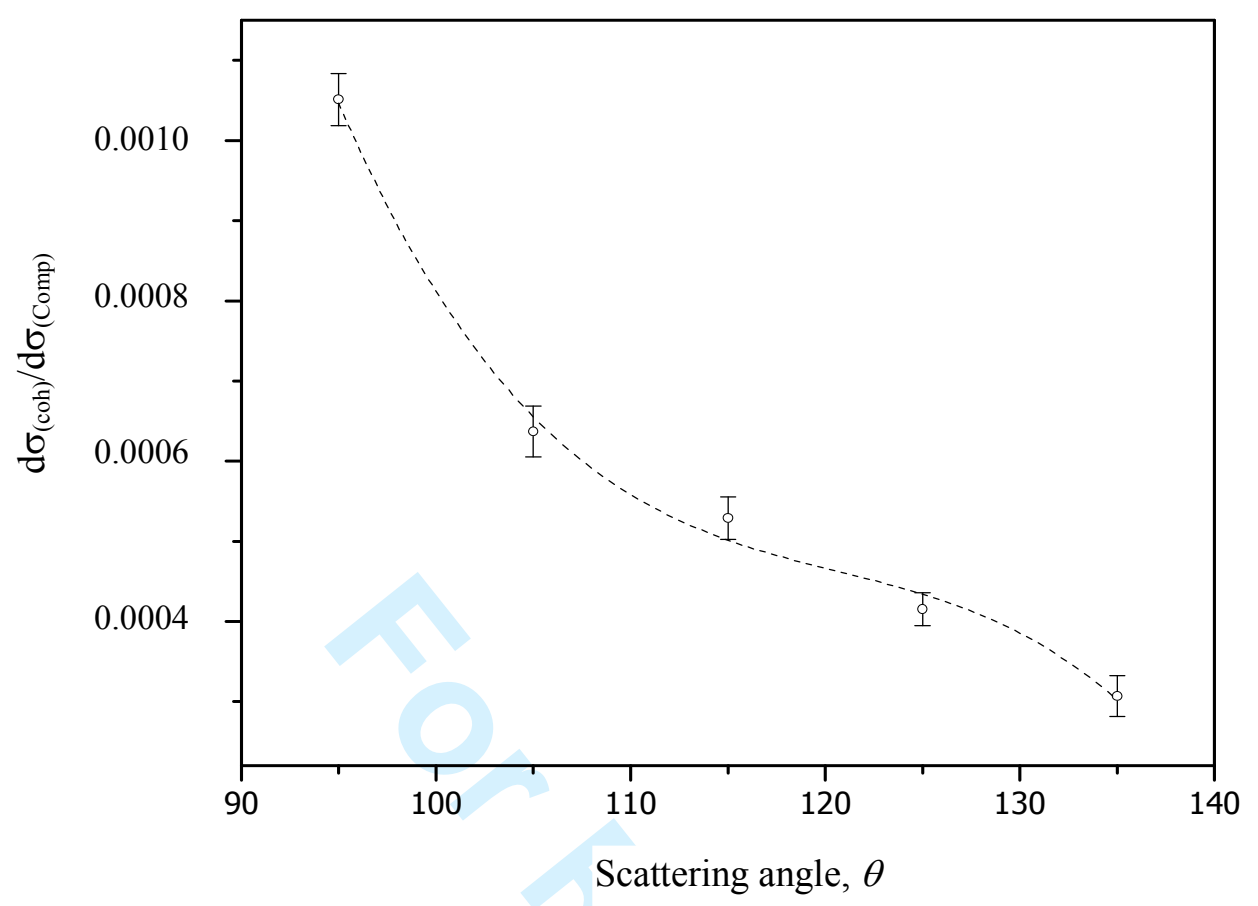

Fig. 7. 


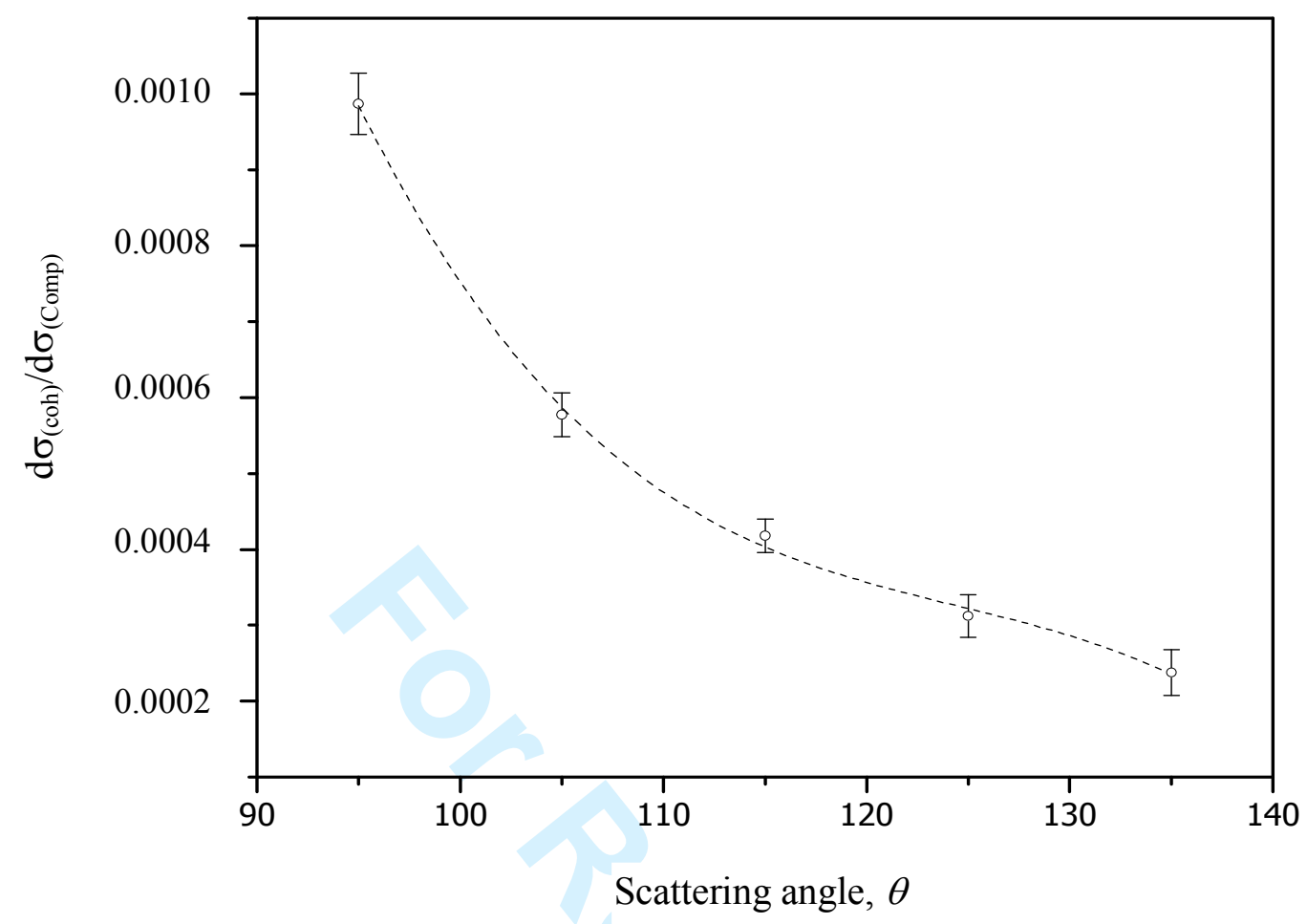

Fig. 8. 
Table 1.

\begin{tabular}{llll}
\hline Compounds & Mean atomic number & Mass thickness $\left(\mathrm{g} / \mathrm{cm}^{2}\right)$ & $\sigma_{\text {coh }} / \sigma_{\text {Comp. }}$ \\
\hline $\mathrm{BaSO}_{4}$ & 17.33 & 0.371 & 1.359 \\
$\mathrm{CaF}_{2}$ & 12.67 & 0.370 & 0.292 \\
$\mathrm{Mg}_{2} \mathrm{SiO}_{4}$ & 10.00 & 0.372 & 0.167 \\
$\mathrm{MgSO}_{4}$ & 10.00 & 0.189 & 0.178 \\
$\mathrm{ZnSO}_{4} 7\left(\mathrm{H}_{2} \mathrm{O}\right)$ & 5.48 & 0.225 & 0.156 \\
& & & \\
\hline \hline
\end{tabular}

